\title{
ANALYSIS AND EVALUATION OF MARKET AND FINANCIAL RISKS IN SMALL AND MEDIUM-SIZED ENTERPRISES
}

\begin{abstract}
The essence of the article is based on the collected and processed data from the survey to analyze, assess and evaluate the impact of the factor, which is the number of employees, on the market and financial risks, identified by managers of the SMEs in the Zilina region of Slovakia. The analysis of market and financial risks is carried out through the analysis of the selected statistical characteristics, using the point and interval estimates and methods of mathematical statistics. Interval estimation enables to determine not only the best estimate, but the entire interval with a certain probability of possible estimates of the mean value of the market and financial risks of a basic file, since the managers of an enterprise are more interested in intervals than in a point value. Results of the survey showed that the number of employees has an impact on the mean value of the market and financial risks of the SMEs in the Zilina region and therefore it is not possible to underestimate it.

Keywords: risk, management, analysis, assessment, evaluation, small and medium-sized enterprise
\end{abstract}

\section{Introduction}

The enterprise is facing constant changes in the business environment and the way to deal with these changes also depends on the ability of the enterprise to adapt and accept the variability of everyday life [1], [2]. In the interests of each management of the enterprise, whether it is small or medium-sized, risk management and the assessment of the current market and financial situation in relation to the potential risks should be commonplace [3]. Small and medium-sized enterprises (SMEs) in Slovakia do not pay sufficient attention to risks, whether market or financial, they do not form the prerequisites, or preventive measures of the risks assessed, which would prevent the problem or the financial crisis in the enterprise.

The economic performance of small and medium-sized enterprises has a major share of the production capacity and employment, and as Kozubikova, Homolka and Kristalas document, the presence of a thriving SMEs sector is one of the characteristic features of the developed economies [4]. Small and medium-sized business is no longer perceived as a social good to be maintained despite its economic costs, but on the contrary, a significant contribution to economic development. In today's world, small and medium-sized enterprises are increasingly perceived as the primary tools for the development of entrepreneurship, while they are not contributing to job creation and socio-political stability, but to the innovation and the competitiveness of the national economy, as well [5]. According to a [6], big companies are the driving force behind the globalization, which cooperate in a horizontal position with the competitors and in a vertical position with the key suppliers and customers. For this reason, the large enterprises work with the growing number of specialised small and medium-sized enterprises, helping them to ensure sufficient flexibility.

The Slovak economy is greatly dependent on the small and medium-sized enterprises, because they create $72 \%$ of job positions and $67 \%$ of the added value that extends well beyond the EU averages ( $67 \%$ and $58 \%$ ). The majority of enterprises operate in the field of services and retail trade sectors, but production also represents an important sector, although it does not include a very high number of SMEs, accounting for $25 \%$ of the jobs and $22 \%$ of the added value creating the SMEs within the corporate economy [7].

Considering the Slovak Republic, regional disparities constitute a particularly important problem. The Slovak Republic has shown the highest level of regional disparities among the countries of the OECD in the five-year average for the period 1996 - 2000. On the contrary, as documented by the Habanik, Hostak and Kutik, the degree of regional disparities was even more developed in the years of $2002-2010$ [8]. Although the economic performance across the country converges to the European level, the economic growth is, however, concentrated in the Bratislava region and the economic performance of the predominantly rural

\footnotetext{
* ${ }^{1}$ Maria Hudakova, ${ }^{2}$ Jan Dvorsky, ${ }^{1}$ Katarina Buganova, ${ }^{2}$ Ludmila Kozubikova

${ }^{1}$ Department of Crisis Management, Faculty of Security Engineering, University of Zilina, Slovakia

${ }^{2}$ Department of Enterprise Economics, Faculty of Management and Economics, Tomas Bata University in Zlin, Czech Republic

E-mail: maria.hudakova@fbi.uniza.sk
} 
Table 1 Classification of the frequency of SMEs according to the number of employees [10], [11]

\begin{tabular}{cccc}
\hline \multirow{2}{*}{ Risk } & & SME & Medium-sized enterprise \\
\cline { 2 - 4 } & Microenterprise & Small enterprise \\
(up to 10 employees) & $(10-50$ employees $)$ & 199 employees) \\
Financial & 66 & 16 & 15 \\
Market & 92 & 27 & 12 \\
\hline
\end{tabular}

regions still lag behind. In this context, there is a particularly important need to examine the economic phenomena of the Slovak Republic, not only at the national but at the regional level, as well.

\section{Data, methodology and methods}

The aim of article is to analyze, assess, and evaluate the impact of the factor, which is the number of employees, on the market and financial risks, identified by the managers of the SMEs in the Zilina region of the Slovak Republic, based on obtained and processed data from the survey. The analysis of market and financial risk is carried out through the analysis of the selected statistical characteristics, using the point and interval estimate and methods of mathematical statistics (analysis of variance). The number of employees in the enterprise is an important factor, which may or may not affect the assessment of the market and the financial risks and their control method. Result of the analysis of the market and financial risks' selected statistical characteristics is a point estimate of the mean value and variance of risks, when evaluating managers of the SMEs. Then, using the statistical testing, the conditions for the implementation of interval estimates (two-sided confidence interval) were determined. Determination of the impact of market and financial risks from the perspective of the number of employees in the SMEs, using the point estimate is a place of a particular point estimate of a mean value of market and financial risks, where the value of risks will lie on with a probability of 0.95 , whereas the managers of enterprise are more interested in interval as the point value. This is a more accurate representation of the value of market and financial risks and its variance not only from the sample, i.e., a random set of SMEs, but the broader interval representation of the sample, i.e. the basic set of risks for the SMEs. Results obtained from the survey are based on the business experience of the SMEs' owners and managers and their attitude to risk, as well as their ability to manage the risk.

In order to meet the stated objective, empirical methods of examination (questionnaire, interview with the competent persons of SMEs), statistical induction of applying statistical methods were used, that is, the analysis of variance using the quantitative tools of statistics (percentage, average values, heteroscedasticity, Cochran's test, Bartlett's test, KolmogorovSmirnov test, F-test, Kruskal-Wallis test, point and interval estimate, graph of the mean values) and statistical software SPSS Statistics [9].

In 2013 - 2015, a statistical survey of business risks of small and medium-sized enterprises in the Zilina region was realized, within the framework of the project FaME/13/MSPRISK: „The recent trends in the area of business risks faced by the small and medium-sized enterprises in the selected regions of the Czech Republic and Slovakia“. In the Zilina region, 164 small and medium-sized enterprises were polled, in the form of empirical research (questionnaires and interviews with the competent persons from SMEs).

The structure of the enterprises was as follows: $17 \%$ in the production, $21 \%$ in trade activities, $17 \%$ in construction business, $6 \%$ in transport, $1 \%$ in agriculture, and the largest share of $38 \%$ formed enterprises doing business in other sectors (consulting, distribution, etc.). In the Zilina region, $80.49 \%$ of business owners stated the market risk as the biggest risk of the business at the moment and $58.54 \%$ mentioned financial risk as the second key risk of business [10].

The survey shows that $67.68 \%$ of enterprises can largely manage financial risks, $23.17 \%$ claims they can properly manage financial risks. Only $1.83 \%$ thinks that they cannot manage the financial risks. This is admittedly a subjective assessment of their own abilities; it is nevertheless possible to say that this capability may be partially supported even by fairly decent educational structure of the entrepreneurs. Point estimates have been calculated on the basis of selected statistical characteristics (SSC), listed in Table 1 and Table 2, which are necessary for the processing of mathematical statistics method, i.e. analysis of variance: $\mu$ - average value of the risk to the enterprise, $\sigma$ - standard deviation of the value of the risk to the enterprise, $\sigma^{2}$ - variance of the values of the risk to the enterprise.

According to the stated purpose in the introduction of the article and with use of statistical methods and tools, it was examined whether or not the factor such as the number of employees in the enterprise in the Zilina region has an impact on mean (average) values of the market and financial risks. To meet the objective, the statistical induction has been used, which consists of a wide range of statistical methods and its findings, obtained from the sample extends the base file. Results of statistical induction have been processed using the point estimate. Thus it was possible to find an estimate of the mean value of the market and the financial risks of the base file using a single value or point. 
Table 2 Point estimates of statistical characteristics of the financial and market risks [10], [11]

\begin{tabular}{|c|c|c|c|c|}
\hline \multirow[b]{2}{*}{ Risk } & \multirow[b]{2}{*}{ SSC } & \multicolumn{3}{|c|}{ SME } \\
\hline & & $\begin{array}{c}\text { Micro-enterprise } \\
\text { (up to } 10 \text { employees) }\end{array}$ & $\begin{array}{c}\text { Small enterprise } \\
(10 \text { - } 50 \text { employees })\end{array}$ & $\begin{array}{l}\text { Medium-sized enterprise } \\
\text { (up to } 499 \text { employees) }\end{array}$ \\
\hline \multirow{3}{*}{ Financial } & $\mu$ & 31.74 & 40.33 & 34.36 \\
\hline & $\sigma$ & 13.48 & 13.95 & 14.74 \\
\hline & $\sigma^{2}$ & 181.92 & 194.52 & 217.45 \\
\hline \multirow{3}{*}{ Market } & $\mu$ & 52.29 & 51.22 & 55.67 \\
\hline & $\sigma$ & 19.53 & 16.17 & 20.73 \\
\hline & $\sigma^{2}$ & 381.43 & 261.47 & 429.73 \\
\hline
\end{tabular}

Table 3 Analysis of variance of market risk values

\begin{tabular}{ccc}
\hline & Number of enterprises & The average in group \\
\hline Micro-enterprise & 66 & 42.77 \\
Small enterprise & 16 & 61.57 \\
Medium-sized enterprise & 15 & 48.36 \\
\cline { 2 - 3 } & & P- value $=0.042$ \\
\hline
\end{tabular}

Then, the quantitative method of "analysis of variance" was used. The analysis of variance was set using either a parametric or non-parametric test. Two essential conditions had to be met for calculation of the parametric tests and it was chosen that the resulting $\mathrm{p}$-value of the market and financial risks of the homoscedasticity test (i.e. identity of variance) and the test to verify the normality of groups of SMEs, must be higher than the level of significance of 0.05 . Evaluation of differences in mean values of the market and financial risks among the groups of the SMEs was the result of the analysis of variance. Using the interval estimate only a single best estimate was identified. However, the whole interval of potential estimates of the mean value of the market and the financial risks is of a base file with a probability of 0.95 .

\subsection{Analysis and assessment of selected statistical characteristics of the market risk}

The parametric test of mean values of the risk could not be used for the analysis of variance of the market risk. The non-parametric test of market risk medians was realised in the three groups of SMEs according to the number of employees in the Zilina region, whereas the conditions have been met. The condition of homoscedasticity - the identity of variances of different groups has been verified using the following tests: Bartlett's test: $p$-value $=0.649$.

From results of the individual tests can be concluded that the resulting p-value was higher than the level of significance that was chosen, in all the tests. The condition of the normal distribution of market risk in enterprises, according to the number of employees using the Kolmogorov-Smirnov test included: p-value of enterprises with the number of employees up to 9 is 0.01 ; $p$-value of enterprises with the number of employees up to 50 is 0.571 ; $p$-value of enterprises with the number of employees up to 499 is 0.555 .

Regarding the level of significance, an assumption that microenterprise risk assessment comes from the normal distribution was refused.

In relation to the fact that the calculated p-value of the Kruskal-Wallis non-parametric test of the analysis of variance is smaller than 0.05 (Table 3 ), one can say that there are statistically significant differences among medians of the values of the market risk, according to the number of employees of small and mediumsized enterprises in the region of Zilina.

Graphic analysis of the market risk, Figure 1, confirmed the test results using the methods of mathematical statistics "Analysis of variance". It was confirmed that the number of employees has an impact on the mean value of the market risk designated by managers of SMEs.

\subsection{Analysis and assessment of selected statistical characteristics of the financial risk}

The parametric test of mean values of the risk for the analysis of variance of the financial risk could not be used. The non-parametric test of financial risk medians was realised in three groups of SMEs, according to the number of employees in the Zilina region, whereas the conditions have been met. The condition of homoscedasticity -the identity of variances 
Table 4 Analysis of variance of financial risk values

\begin{tabular}{ccc}
\hline & Number of enterprises & The average in group \\
\hline Micro-enterprise & 92 & 66.05 \\
Small enterprise & 27 & 62.50 \\
Medium-sized enterprise & 112 & 73.54 \\
\cline { 2 - 3 } & & P- value $=0.009$ \\
\hline
\end{tabular}

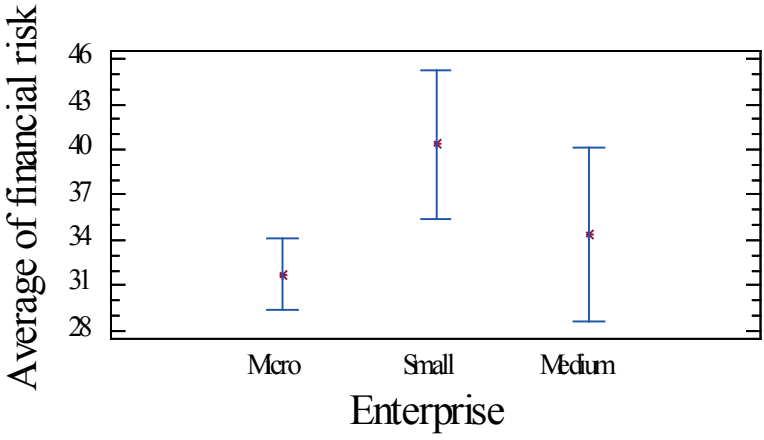

Figure 1 Graph of the average values of market risk in groups of SMES

of different groups has been verified using the following tests: Cochran test: $p$-value $=0.934$.

From results of the individual tests can be concluded that the resulting p-value was higher in all tests than the level of significance that was chosen. The condition of the normal distribution of financial risk in enterprises, according to the number of employees using the Kolmogorov - Smirnov test included: $p$-value of enterprises with the number of employees up to 9 is 0.003 ; $p$-value of enterprises with the number of employees up to 50 is 0.701 ; p-value of enterprises with the number of employees up to 499 is 0.433 .

On the surface the significance, an assumption that microenterprise risk assessment with the number of employees up to 9 come from the normal distribution was refused.

In relation to the fact that the calculated $p$-value of the Kruskal-Wallis non-parametric test of the analysis of variance is smaller than 0.05 , one can say that there are statistically significant differences among medians of the values of financial risk, according to the number of employees of small and mediumsized enterprises in the region of Zilina, with the reliability of 0.95 . Table 4 shows that the median assessment of the small enterprises in relation to financial risks is on average about a third higher than the risk of micro and medium-sized enterprises in the Zilina region in Slovakia.

Graphic analysis of financial risk, Figure 2 confirmed the test results using the methods of mathematical statistics "Analysis of variance". It was confirmed that the number of employees has impact on the mean value of the financial risk designated by managers of SMEs.

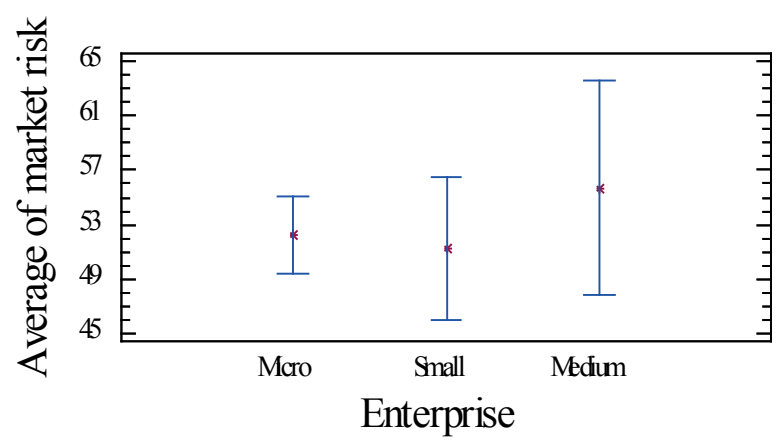

Figure 2 Graph of the average values of financial risk in groups of SMEs

\subsection{Interval estimates of the statistical characteristics of financial and market risks}

Based on the knowledge of the selected statistical characteristics of the assessment of market and financial risks by managers of the SME from the Zilina region (Tab. 2), the probability model of normal distribution of mean value of market and financial risks was found. Subsequently, the generalised conclusions on the assessment and evaluation of the market and financial risks, by the managers of the SME in the Zilina region in the Slovak Republic were drawn and a base file was created. An important factor in statistical induction was development of the calculation of interval estimates with a specified reliability of 0.95 (estimate reliability). Since it was a sample of managers and owners of SMEs in the Zilina region, expressing general conclusions on the assessment of market and financial risks, it was counted on the potential uncertainty with probability of 0.05 . Point estimates of the sample file of the selected statistical characteristics, such as the mean value, variance and standard deviation of financial and market risks, calculated in Table 2 represent point estimates of the base file, which are the basis for determining of the interval estimates.

Interval estimates of the base file, such as the mean value and standard deviation of financial and market risks of the assessment of the SME managers, with the probability of 0.95 , are calculated in Tables 5 and Table 6: $\mu_{\mathrm{d}}$ - the lower limit of the interval estimate of the mean value with reliability $95 \%$; $\mu_{\mathrm{h}}$ - the upper limit of the interval estimate of the mean value with reliability $95 \%$; $\sigma_{\mathrm{d}}$ - the lower limit of the interval estimate of standard deviation; $\sigma_{\mathrm{h}}$ - the upper limit of the interval estimate of standard deviation. 
Table 5 Interval estimates of the mean value of financial and market risk

\begin{tabular}{|c|c|c|c|c|c|c|}
\hline \multirow{3}{*}{ Risk } & \multicolumn{6}{|c|}{ SME } \\
\hline & \multicolumn{2}{|c|}{$\begin{array}{c}\text { Micro-enterprise } \\
\text { (up to } 10 \text { employees) }\end{array}$} & \multicolumn{2}{|c|}{$\begin{array}{c}\text { Small enterprise } \\
\text { (10 - } 50 \text { employees) }\end{array}$} & \multicolumn{2}{|c|}{$\begin{array}{c}\text { Medium-sized enterprise (up to } 499 \\
\text { employees) }\end{array}$} \\
\hline & $\mu_{\mathrm{d}}$ & $\mu_{\mathrm{h}}$ & $\mu_{\mathrm{d}}$ & $\mu_{\mathrm{h}}$ & $\mu_{\mathrm{d}}$ & $\mu_{\mathrm{h}}$ \\
\hline Financial & $28.42^{*}$ & $35.05^{*}$ & 32.60 & 48.05 & 24.45 & 44.27 \\
\hline Market & $48.24^{*}$ & $56.33^{*}$ & 43.02 & 59.42 & 45.39 & 65.94 \\
\hline
\end{tabular}

"Condition of normal distribution of data in the group has not been met.

Table 6 Interval estimates of the standard deviation of financial and market risk

\begin{tabular}{|c|c|c|c|c|c|c|}
\hline \multirow{3}{*}{ Risk } & \multicolumn{6}{|c|}{ SME } \\
\hline & \multicolumn{2}{|c|}{$\begin{array}{c}\text { Micro-enterprise } \\
\text { (up to } 10 \text { employees) }\end{array}$} & \multicolumn{2}{|c|}{$\begin{array}{l}\text { Small enterprise } \\
\text { (10 - } 50 \text { employees) }\end{array}$} & \multicolumn{2}{|c|}{$\begin{array}{c}\text { Medium-sized enterprise (up to } 499 \\
\text { employees) }\end{array}$} \\
\hline & $\sigma_{\mathrm{d}}$ & $\sigma_{\mathrm{h}}$ & $\sigma_{\mathrm{d}}$ & $\sigma_{\mathrm{h}}$ & $\sigma_{\mathrm{d}}$ & $\sigma_{\mathrm{h}}$ \\
\hline Financial & $11.51^{*}$ & $16.2^{*}$ & 10.21 & 21.99 & 10.30 & 25.87 \\
\hline Market & $17.06^{*}$ & $22.8^{*}$ & 16.32 & 28.40 & 11.45 & 27.45 \\
\hline
\end{tabular}

${ }^{*}$ Condition of normal distribution of data in the group has not been met.

Based on the results of the Kolmogorov-Smirnov test of the mean value of the financial and market risks, analyzed and evaluated in subsections 2.1 and 2.2, one cannot take into account the interval estimates of the selected statistical characteristics (the mean value and standard deviation) with a probability of 0.95 . The reason is that the assessment of the market and financial risks by managers in microenterprises does not follow the condition of probability model of normal distribution. Interval estimates of the mean value and standard deviation of market and financial risk by managers of SMEs in the Zilina region were determined using the method of mathematical statistics with the probability of 0.95 . Based on this fact one can conclude that there is a high degree of significance of results analyzed and assessed in the processed survey.

\section{Evaluation of the results}

Based on the results of the survey analysis of market and financial risks of the SMEs, through the analysis of the basic statistical characteristics of point and interval estimates and methods of mathematical statistics, one can conclude that the number of employees has an impact on the mean values of the market and financial risks identified by managers of the SMEs in the Zilina region. Therefore, their impact cannot be underestimated. Defining the point and interval estimation the interval of market and financial risks impact for managers from the perspective of the number of employees in SMEs in Slovakia was set.

Based on calculations, an interesting finding was obtained that the greatest impact of financial risk, in view of the number of employees in SMEs in Zilina region, has been identified in small enterprises. The reason may be the growing number of fraud cases in the fields of accounting, operations or customer service. If a small enterprise management is not sufficiently informed of all the processes of the enterprise and the lack of funds is forcing it to restrict the costs of the high-quality external services in the fields of accounting, or safety, it may affect the conduct of employees in a negative way. An unclear distribution of responsibilities, competence and powers is a frequent source of disagreement at the workplace, as well as of possible financial losses as a result of failure to comply with the stated objectives.

The impact of the number of employees on the occurrence of market risk in the SMEs in the Zilina region is the highest in the medium-sized enterprises, and the lowest among small enterprises. In view of the volume of production and the operation of the market, the medium-sized enterprises are more sensitive than the small ones. Their operation is often very little flexible, or there is too much dependence on the customer, or supplier, which may affect their pricing policy, low load from the perspective of the production capacity and last but not the least, their profits. Those aspects have impact on wage and tax policy of the enterprise. The rising costs are the major source of risk for the SMEs in this area.

Financial risks in the form of operational risks, which are usually caused by a failure of the human factor or technological failure, may lead to financial losses. Those are the risks that are mostly short-term in duration, but the possible negative effects of the crisis situation arising as a result may have extensive or disastrous consequences (risks to health, life, property). One of the most common causes of the ending of an enterprise includes incorrect calculation of minimum capital and very often underestimated calculation of unit costs, incorrectly calculated prices of goods and services, errors in accounting (tax, levy), 
high input investment and insufficiently or improperly secured funding sources (own, foreign). From the point of view of the financial burden, the largest source of risks is the high tax load, which acts negatively on the amount of the total costs of work and is administratively challenging, as confirmed by the results of the survey.

The SMEs can manage risks in several ways. One of the options, which, however, a lot of SMEs do not use, is to create financial reserves of the enterprise for the period of the recession. This is due to limited financial resources. Therefore, it is recommended in the field of SMEs to move risk to the business partners. In terms of functioning of the financial markets and the insurance market, which provides a range of products and credits, one of the most viable ways is to reduce risk by providing security or insurance. A higher level of planning requires reducing the risk by diversifying into different commercial activities. Diversifying risks into the various activities requires combining the financial resources. Securing funding through loan products, or from other available sources to support SMEs, requires the processing of a detailed financial and cash-flow plan, taking into account the potential risks of the business.

\section{Conclusions}

Most of the enterprises abroad integrate risk management into their planning and decision-making process s, i.e. systematically consider the potential risks when taking decisions in the area such as cash-flow management, investment, pricing. They see the implementation of enterprise risk management as the greatest potential for increasing efficiency in risk management. Even in Slovakia, medium-sized enterprises, in an effort to improve risk prevention, should have integrated risk management, i.e. centralize the risk management into one department and create teams composed of different departments to control individual types of risks. The biggest barriers that prevent enterprises in Slovakia from effective control of market and financial risks, are related to problems with the availability of information, whether internal or external data necessary to the evaluation and management of risks, or their integration into the decision-making process. They identify the financial risks only on the basis of the data in the accounts and according to the degree of profitability, after their implementation (establishment). Based on the present experience, many managers are based on the knowledge of the past. However, evaluating the risk only based on own experience and feelings is currently insufficient. Analysis and assessment of the researched factor, such as the number of employees, revealed the impact on the level of market and financial risks cannot be underestimated. Therefore, owners of the SMEs in Slovakia and responsible managers must rethink their approach to the assessment and management of market and financial risks and consider the level of the action of risk resources for the purpose of managing risks arising from them.

\section{Acknowledgment}

Publication of this paper was supported by the Scientific Grant Agency - project VEGA No. 1/0560/16. Risk Management of Small and Medium Sized Enterprises in Slovakia as Prevention of Company Crises.

\section{References:}

[1] AGARWAL, R., ANSELL, J.: Strategic Change in Enterprise Risk Management. Strategic Change-Briefings in Entrepreneurial Finance, 25(4), 427-439, 2016.

[2] BOGODISTOV, Y., WOHLGEMUTH, V.: Enterprise Risk Management: A Capability-Based Perspective. Journal of Risk Finance, 18(3), 234-251, 2017.

[3] FRASER, J. R. S., SIMKINS, B. J.: The Challenges of and Solutions for Implementing Enterprise Risk Management. Business horizons, 59(6(SI)), 689-698, 2016.

[4] KOZUBIKOVA, L., HOMOLKA, L., KRISTALAS, D.: The Effect of Business Environment and Entrepreneurs' Gender on Perception of Financial Risk in the Smes Sector. Journal of Competitiveness, 9(1), 36-50, 2017.

[5] BROLL, U. A., MUKHERJEE, S. B.: International Trade and Firms' Attitude towards Risk. Economic Modelling, 64, 69-73, 2017.

[6] LUSKOVA, M., TITKO, M.: Current Trends in Work Motivation and Perceived Risks. Proceedings of the 3rd International Multidisciplinary Scientific Conference on Social Sciences and Arts (SGEM 2016), Bulgaria, 157-164, 2016.

[7] URBANCOVA, H., HUDAKOVA, M.: Employee Development in Small and Medium Enterprise in the Light of Demographic Evolution. Acta Universitatis Agriculturae et Silviculturae Mendelianae Brunensis, 63(3), 1043-1050, 2015.

[8] HABANIK, J., HOSTAK, P., KUTIK, J.: Economic and Social Disparity Development within Regional Development of the Slovak Republic. Economics and Management, 18(3), 457-464, 2013.

[9] HAIR, J. F.: Multivariate Data Analysis. Upper Saddle River, Prentice-Hall, 2010. 


\section{kam Nlkocle}

[10] HUDAKOVA, M., BUGANOVA, K., DVORSKY, J., BELAS, J., DANA, L. P.: Analysis of the Risks of Small and Medium-Sized Enterprises in the Zilina Region. Communications - Scientific Letters of the University of Zilina, 17(1), 34-39, 2015.

[11] BELAS, J., BUGANOVA, K., HOSTAK, P., HUDAKOVA, M., LUSKOVA, M., MACHACEK, J., SOBEKOVA-MAJKOVA, M.: The Business Environment for Small and Medium-Sized Enterprise in the Czech and Slovak Republic. Georg, Zilina, p. $153,2014$. 